\title{
Evaluation of The Diagnostic Role of Non-Coding RNA and Exosomal Related Gene Association in Lung Cancer Fawzia Khalil ${ }^{1}$, Hanan H. Shehata ${ }^{1}$, Nehad Osman ${ }^{2}$, Omar Abdel-Rahman ${ }^{3}$, Marwa Ali ${ }^{1}$ and Ghada Mohamed ${ }^{1}$
}

1 Medical Biochemistry and Molecular Biology Department, 2 Pulmonary Medicine Department, Clinical Oncology and Nuclear Medicine Department, Faculty of Medicine -Ain Shams University

\begin{abstract}
Background: Exosomes are microvesicles that are recently discovered in intercellular communication especially between tumor cells as lung cancer that are important for tumor development and progression.

Objectives: Examine the diagnostic role of serum exosomal LncRNA in lung cancer among Egyptian population.

Methods: Lung cancer characteristic exosomal RNA-based biomarker Lnc-RNA-RP11-510M2.10 was selected based on bioinformatic methods, followed by RT-qPCR validation of their expression in serum of 20 patients with lung cancer and 10 healthy volunteers.

Results: serum exosomal Lnc-RNA-RP11-510M2.10 showed a significant negative association with lung cancer patients in comparison to patients with healthy persons $(\mathrm{p}<0.001)$.

Conclusion: Lnc-RNA-RP11-510M2.10 could be used as diagnostic and prognostic biomarker tools for lung cancer.
\end{abstract}

Keywords: Lung cancer, Exosomal RNA extraction, Lnc-RNA-RP11-510M2.10.

\section{INTRODUCTION}

Lung cancer is the most common cause of cancer death worldwide, nearly $85 \%$ of patients have a group of histological subtypes collectively known as NSCLC, of which lung adenocarcinoma (LUAD) and lung squamous cell carcinoma (LUSC) are the most common subtypes ${ }^{(1)}$.

\section{Risk Factors:}

\section{Tobacco smoking:}

Causes $80 \%$ - $90 \%$ of all lung cancers. Risk factors are typically dose- and duration-dependent, and many carcinogens act synergistically when combined with tobacco smoke. For example, arsenic in drinking water has been associated with lung cancer when combined with exposure to tobacco smoke. Radon, a naturally occurring radioactive gas found in some homes, is estimated to cause 21,000 cases of lung cancer per year ${ }^{(2)}$.

\section{Chronic Obstructive Pulmonary Disease:}

COPD is known as a systemic inflammatory disorder with many pulmonary and extrapulmonary manifestations, as an increased risk for primary lung cancers development ${ }^{(3)}$.

\section{Secondhand or Passive Smoking:}

A significant risk factor and causes $1.6 \%$ of lung cancers ${ }^{(4)}$. Recent study reported that exposure during childhood increase risk by 3.6 fold for lung cancer in adulthood ${ }^{(5)}$.

\section{Diet and Food Supplements:}

Antioxidant vitamins and other micronutrients, as carotenoids, present in fruits and vegetables, decrease the risk of lung as well as other cancers. There are no associations between intakes of different types of fat and lung cancer risk. Conversely, cured meat (e.g., pressed duck, cured pork and sausage), deep-fried cooking, and chili increase risk for lung cancer ${ }^{(6)}$.

\section{Alcohol Intake:}

Is associated with greater risk for lung cancer particularly among people who consume at least 30 $\mathrm{g} / \mathrm{d}$ of alcohol than those who refined from alcohol (7).

\section{Exercise and Physical Activity:}

Data shows that physical activity is associated with lower risk of lung cancer, moderate to high levels of physical activity are associated with a reduction of $13 \%$ to $30 \%$ in lung cancer risk. As a whole, physical activity can aid in reduction of lung cancer risk and mortality among heavy smokers ${ }^{(8)}$.

\section{Air Pollution:}

The long-term of surrounding air pollution as exposure to various polycyclic aromatic hydrocarbon compounds is associated with the risk of lung cancer, most probably by inflammation, oxidative stress, stimulation of a procoagulatory state and disturbance of the autonomic nervous system ${ }^{(9)}$.

It is estimated that $11 \%$ of lung cancers are attributed to urban air pollution among Europeans (10). 


\section{Occupational Exposure:}

It is expected that workers exposed to silica dust and asbestos fiber which are well-known human carcinogens, are at increased risk of developing lung cancer. Uranium miners and nuclear plant workers are also known to have a higher risk of cancer as a result of exposure to radioactive particulate mass ${ }^{(11)}$.

\section{Lung Cancer Susceptibility Genes:}

Mutations in the epidermal growth factor receptor $(E G F R)$ gene are present in $20 \%$ of adenocarcinomas. As a whole, the combination of genetic factors and environmental carcinogens are encountered in the lung cancer pathogenesis ${ }^{(12)}$.

\section{Clinical Presentation:}

Symptoms lung cancer appear at the time of diagnosis. Symptoms that are caused by

1) Primary tumor is: - cough, hemoptysis, chest or rib pain, fatigue, dyspnea, weight loss, digital clubbing.

2) Intrathoracic spread (e.g., Horner syndrome, SVC obstruction).

3) Distant Metastases (e.g., bone pain).

4) Paraneoplastic syndromes, which are not related to the tumor or metastasis but they occur due to ectopic production of hormones from the tumor or the body's reaction to the tumor. They represent about $10 \%$ of lung cancer patients and they are more common among patients with SCLC ${ }^{(13)}$.

\section{Screening:}

The U.S. Preventive Services Task Force (USPSTF) recommends annual low-dose CT to screen for lung cancer in patients 55 to 80 years of age with at least a 30 pack-year history who currently smoke or have quit within the past 15 years. The American Academy of Family Physicians concludes that the evidence is insufficient to recommend for or against low-dose CT screening for lung cancer. This conclusion is based on the fact that the National Lung Screening Trial was performed at major centers with strict protocols (not community hospitals) and $40 \%$ of patients required some type of follow-up study or intervention because of positive results, and that the long-term hazards from cumulative radiation exposure with this screening are unknown. In light of differing guidelines, an approach of shared decision making and educating patients on the potential benefits and risks in relation to their personal health ${ }^{(14)}$.

\section{What are exosomes:}

The term exosome is previously referred to 40 $1,000 \mathrm{~nm}$ vesicles released from different cultured cells. Nowadays, it is referred to vesicles ranging from 40-100-nm released during differentiation of reticulocyte as a result of multivesicular endosome (MVE) fusion with the plasma membrane. Both hematopoietic and non-hematopoietic cell, such as cytotoxic $\mathrm{T}$ cells, platelets, neurons, oligodendrocytes and intestinal epithelial cells, are documented to release exosomes by fusion of MVE with the cell surface. Exosomes have been isolated from diverse body fluids, including semen, blood, urine, saliva, breast, milk, amniotic fluid, ascites fluid, cerebrospinal fluid and bile ${ }^{(15)}$.

\section{The Molecular Composition of Exosomes:}

Membrane proteins that cluster into microdomains at the plasma membrane or at endosomes including tetraspanins (a family of $>30$ proteins that are composed of four transmembrane domains) are also present on exosomes. It was demonstrated that tetraspanins as CD37, CD53, CD63, CD81 and CD82 are first identified in B cell exosomes but other studies demonstrated that tetraspanins also present in exosomes from other sources. Exosomes are rich in lipid rafts associated proteins, such as flotillin and glycosylphosphatidylinositol-anchored proteins.

Concerning the lipid content of the exosomes, exosomes from different cells are highly enriched in cholesterol, sphingomyelin, and hexosylceramides at the expense of phosphatidylcholine and phosphatidylethanolamine as compared to the plasma membrane. Exosomes contain fatty acids that are mostly saturated or monounsaturated. The presence of FAs and high concentration of cholesterol, accounts for their lateral segregation into exosomes during their formation at MVEs. A major discovery is that the exosomal cargo include mRNA and miRNA and that the target cells can translate exosome associated mRNAs into proteins. Recent studies on the exosomes demonstrated that those released by immune cells selectively incorporate miRNA that can be transferred functionally upon fusion with recipient cells. In addition to mRNA and miRNA, exosomal cargo also include a large different species of other small noncoding RNAs, including RNA transcripts overlapping with protein coding regions, repeat sequences, structural RNAs, tRNA fragments, vault RNA, Y RNA, and small interfering RNAs. Exosomes are enriched with RNA profiles relative to that found in the originating cells, indicating the selective incorporation of RNA molecules into exosomes ${ }^{(16)}$.

\section{Nucleic Acid Trafficking Via Exosomes:}

Studies have shown that tumor-derived exosomes have different microRNA profiles in many cancers, as breast, lung, prostate and ovarian. 
Also, other studies have revealed the oncomicroRNAs transfer to target cells, and their ability to modify target pathways in host tissue. These studies have shown that the expression of both proand anti-tumor microRNAs is responsible for oncogenic functions of microRNA and that microRNA transport and signaling processes which are important in cancer essentially require exosomes. the functional transfer of mRNA and DNA in exosomes is observed. And analysis shows exosomes containing mutated DNA fragments and mRNA transcripts participate in the growth and proliferation of many primary and metastatic cancers ${ }^{(17)}$.

\section{Classification of non-coding RNA}

ncRNAs are classified according to the length of transcript into two groups:

1- Small ncRNAs (<200 bp), as: a-Transfer RNAs (tRNAs),

b-Ribosomal RNAs (rRNAs), essential for translation machinery

c-Small nucleolar RNAs (snoRNAs), essential for splicing

d-microRNAs (miRNAs), e-Small interfering RNAs (siRNA), f-PIWI-interacting RNAs(piRNA), g-Antisense RNAs, h- Promoter-associated RNAs(PARs) 2- Long ncRNAs (>200 bp) transcribed by RNA polymerase II (Pol II) from genomic loci with similar chromatin states to mRNAs; they are often 5 '-capped, spliced and polyadenylated; in most instances, they lack any biochemical distinction from mRNAs besides the absence of a translated $\mathrm{ORF}^{(18)}$.

\section{Classifications of IncRNA:}

The major classification is according to genomic location (Fig 1):

-Intergenic (lincRNAs): majority, located between two protein-coding genes.

-Intronic: - located within introns of protein-coding genes.

-Bidirectional promoter: transcribed within $1 \mathrm{~kb}$ of promoters in the opposite direction from the protein-coding transcript.

-Enhancer (elncRNAs): generally, $<2 \mathrm{~kb}$, transcribed from enhancer regions of the genome.

-Sense lncRNAs: transcribed from the sense strand of protein-coding genes, can overlap introns and part or all of the exon.

-Antisense lncRNAs: transcribed from the antisense strand of protein-coding genes, can overlap an exon of the protein-coding gene found in the sense strand, an intron, or both ${ }^{(19)}$.

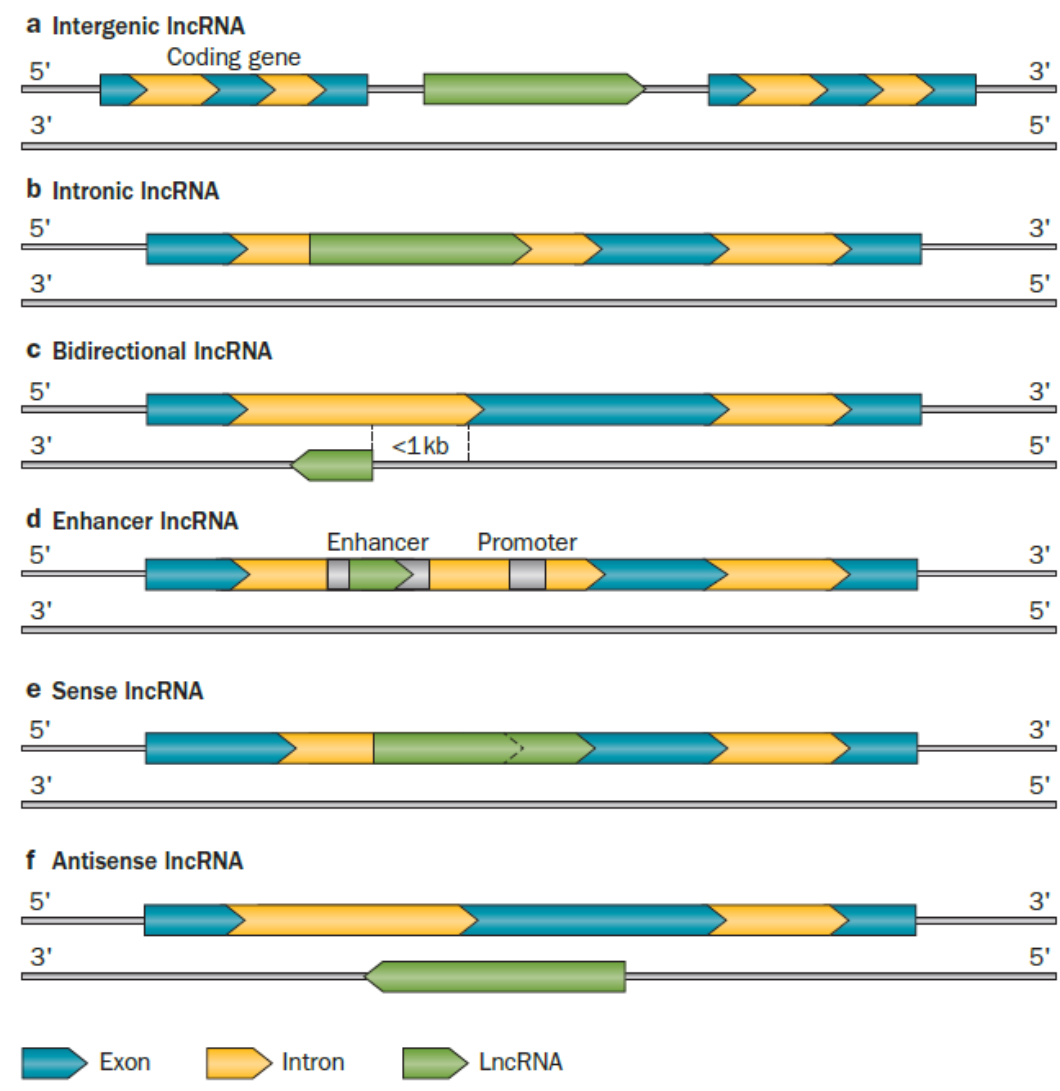

Figure 1: - lncRNAs Classification based on their genomic location 


\section{Functions of IncRNAs:}

LncRNAs function by modulating the transcription and translation of protein-coding genes. Unlike miRNAs, which commonly participate in mRNA degradation or regulate mRNA translation, lncRNAs regulate the expression of target genes through multiple mechanisms at different levels. IncRNAs can interact directly with DNA, mRNA, or proteins to regulate chromatin modification or structure, transcription, splicing, and translation, so as to regulate a variety of physiological and pathological processes such as cell proliferation or differentiation, tumorigenesis, or drug resistance (44). First, at the transcriptional level, lncRNAs (1) act as decoys for TFs or RNAPII to disrupt their binding to promoters/ enhancers of target genes, thus promoting or suppressing gene expression; (2) interact directly with TFs and alter their modification or localization to regulate gene transcription; (3) interact with DNA and form scaffolds for TFs, thus affecting target gene transcription; and (4) act as competitive endogenous RNAs (ceRNAs) to control target gene transcription. Second, at the post-transcriptional level, lncRNAs (1) act as precursors of siRNAs or miRNAs, leading to decreased expression of their target genes, (2) form double stranded RNA complexes with mRNAs and protect them from degradation, and (3) regulate the alternative splicing of pre-mRNAs to produce different transcripts. Lastly, at the epigenetic level, lncRNAs (1) interact with proteins associated with histone modifications to modify the methylation, acetylation or ubiquitination of histones; (2) get involved in gene silencing by regulating DNA methylation in the promoter region of target genes; and (3) get involved in chromatin remodeling or conformational alterations by binding to chromatin modification complexes, which is important for gene transcription ${ }^{(20)}$.

In this study, we performed bioinformatics to detect IncRNA related to lung cancer which is lncRNA RP11-510M2.10 and its associated genes as Rab27A.

\section{SUBJECTS AND METHODS}

The present study included thirty subjects, who were recruited from Ain Shams University hospitals, Egypt, a written informed consent was properly executed and documented as approved by Research Ethical Community (REC) of Faculty of
Medicine, Ain Shams University. They were classified into two groups; Group A (Malignant group): Patients with bronchogenic carcinoma. Tumor stage was revised according to the TNM staging system of the American Joint Committee on Cancer, Lung, in: AJCC Cancer Staging ${ }^{(21)}$.

Group B (Control group): healthy volunteers, with matching age and sex to the patients' groups.

Methods

1- Bioinformatics' Analysis was done to retrieve promising exosomal RNA- biomarkers relevant to Lung cancer based on previous microarray studies.

2- Blood samples were collected from all participants and centrifuged to collect sera.

3- Purification of exosomes followed by Exosomal RNA isolation by following the manufacturer's instructions of the exoRNeasy Serum/Plasma Midi Kit (50) Catalog no. 77044, provided by QIAGEN.

4- Reverse Transcription was performed to the Exosomal extracted RNA by Real-Time two-step RT-PCR using QuantiTect@ Reverse Transcription Kit provided by QIAGEN as per manufacturer's protocol.

5- Quantitative real time PCR (Polymerase Chain Reaction) using QuantiTect ${ }^{\circledR}$ SYBR ${ }^{\circledR}$ Green PCR Kit (Qiagen, Germany): was performed to detect the levels of exosomal lncRNA RP11$510 \mathrm{M} 2.10$ in sera, by forming $2 \mathrm{x}$ QuantiTect SYBR Green PCR Master Mix cDNA, all steps followed the manufacturer's suggested protocol.

6- The PCR program was as follows: firstly, denaturation at $95^{\circ} \mathrm{C}$ for $15 \mathrm{~min}$; then 40 cycles of denaturation for $15 \mathrm{sec}$. at $94^{\circ} \mathrm{C}$; after that annealing for $30 \mathrm{sec}$. at $55^{\circ} \mathrm{C}$; and finally, extension for $30 \mathrm{sec}$. at $72^{\circ} \mathrm{C}$.

\section{RESULTS}

No statistical significant differences were noted regarding age, sex, alcoholic consumption or family history among the two groups ( $p>0.05$ ). However, there was statistical significance occurrence of lung cancer among smokers even heavy smokers than light smoker and person who were occupationally exposed than non-exposed. Details of the demographic and clinical data are shown in Tables $1 \& 2$.

Table 3 shows the differential expression of serum exosomal Lnc-RNA-RP11-510M2.10 among the different study groups, it was higher among the control group than among malignant group with high statistical significance. 
Evaluation of The Diagnostic Role of Non-Coding RNA...

Table (1): The Age in Different Groups of the Study (In Years)

\begin{tabular}{|c|c|c|c|c|c|c|}
\hline GROUP & N. & Median & Range & Mean \pm SD & $\mathbf{F}^{(\mathbf{a})} \mathbf{p}$ & $\chi^{\mathbf{2 ( b )}} \mathbf{p}$ \\
\hline Malignant group & 20 & 51.5 & $35-68$ & $50.45 \pm 12.275$ & 1.162 & 2.4 \\
\cline { 1 - 5 } Normal controls & 10 & 53.5 & $34-79$ & $54.20 \pm 15.483$ & 0.324 & 0.301 \\
\hline
\end{tabular}

a: One-Way ANOVA test

b: Kruskal wallis test

Table (2): Study population demographic and clinical characteristics

\begin{tabular}{|c|c|c|c|c|c|}
\hline \multicolumn{2}{|c|}{ Clinicopathological Factors } & $\begin{array}{l}\text { Malignant } \\
\text { group }(20)\end{array}$ & $\begin{array}{c}\text { Normal } \\
\text { Controls(10) }\end{array}$ & $\chi^{2(a)}$ & $\mathbf{P}$ \\
\hline Sex: & $\begin{array}{l}\text { Male (16) } \\
\text { Female (14) }\end{array}$ & $\begin{array}{l}12(60 \%) \\
8(40 \%)\end{array}$ & $\begin{array}{l}4(40 \%) \\
6(60 \%)\end{array}$ & 3.333 & 0.189 \\
\hline Smoking: & $\begin{array}{l}\text { Smoker (16) } \\
\text { Non-Smoker (14) }\end{array}$ & $\begin{array}{l}14(70 \%) \\
6(30 \%) \\
\end{array}$ & $\begin{array}{l}2(20 \%) \\
8(80 \%)\end{array}$ & 7.673 & $0.022 *$ \\
\hline $\begin{array}{l}\text { Smoking index } \\
(\mathbf{2 3})\end{array}$ & $\begin{array}{l}\text { Heavy smoker (12) } \\
\text { Light smoker (4) }\end{array}$ & $\begin{array}{l}12(60 \%) \\
2(10 \%)\end{array}$ & $\begin{array}{l}0(0 \%) \\
2(20 \%)\end{array}$ & 6.8 & $0.033^{*}$ \\
\hline $\begin{array}{l}\text { Occupational } \\
\text { Exposure }\end{array}$ & $\begin{array}{l}\text { Exposed (12) } \\
\text { Not Exposed (18) }\end{array}$ & $\begin{array}{l}11(60 \%) \\
9(40 \%) \\
\end{array}$ & $\begin{array}{l}1(10 \%) \\
9(90 \%)\end{array}$ & 7.253 & $0.027^{*}$ \\
\hline Family History & $\begin{array}{l}\text { +Ve Family History (10) } \\
\text {-Ve Family History (16) }\end{array}$ & $\begin{array}{c}8(40 \%) \\
12(60 \%) \\
\end{array}$ & $\begin{array}{l}2(20 \%) \\
8(80 \%) \\
\end{array}$ & 1.905 & 0.386 \\
\hline $\begin{array}{c}\text { Alcohol } \\
\text { Consumption } \\
\end{array}$ & $\begin{array}{l}\text { Alcoholics (8) } \\
\text { Non-Alcoholics (22) }\end{array}$ & $\begin{array}{c}7(35 \%) \\
13(65 \%)\end{array}$ & $\begin{array}{l}1(10 \%) \\
9(90 \%)\end{array}$ & 2.4 & 0.301 \\
\hline Histopathology & $\begin{array}{l}\text { Adenoid cystic (2) } \\
\text { Undifferentiated lung } \\
\text { cancer (3) } \\
\text { Large cell carcinoma (3) } \\
\text { Adenocarcinoma (6) } \\
\text { Squamous cell } \\
\text { carcinoma(6) }\end{array}$ & $\begin{array}{l}2(10 \%) \\
3(15 \%) \\
3(15 \%) \\
6(30 \%) \\
6(30 \%)\end{array}$ & --------- & -- & - \\
\hline
\end{tabular}

Table (3): Differential expression of serum exosomal Lnc-RNA-RP11-510M2.10 among the study groups:

\begin{tabular}{|c|c|c|c|c|c|c|}
\hline \multirow{2}{*}{ Group } & \multicolumn{5}{|c|}{ RQ } & \multirow{2}{*}{ P** } \\
\cline { 2 - 7 } & Mean \pm SD & Minimum & Maximum & Median & Mean Rank & \\
\hline Malignant group & $0.6261 \pm 0.27$ & 0.17 & 1.64 & 0.62 & 12.15 & \multirow{2}{*}{0.00} \\
\hline Normal controls & $2.8716 \pm 1.68$ & 0.26 & 5.25 & 2.71 & 32.40 & \\
\hline
\end{tabular}

\section{DISCUSSION}

Lung cancer is one of the most common diagnosed cancers and leading cause of cancer-related death worldwide. It accounted for $17 \%$ and $9 \%$ of all cancers among males and females, respectively. Also, it represents $19 \%$ of all cancer-related deaths (22). Recently, exosomes are considered a promising therapeutic target and screening test for lung cancer. One of the important constituent of exosomes are mRNA and ncRNAs as miRNA and lncRNA that are important in cell signaling and homeostasis ${ }^{(23)}$, they are considered as cancer specific biomarkers and so, they are used nowadays as non-invasive test for detection of cancer as they can be detected in the serum.

In this communication, we examined the Differential expression of serum exosomal
LncRNA-RP11-510M2.10. Depending on an in silico data analysis; among the study groups. We assumed that it was the first study to examine the expression of Lnc-RNA-RP11-510M2.10 in relation to lung cancer. Verification of this data in wet lab revealed a highly statistical difference among the study groups where level of its expression was low among the malignant group and high among the control group.

LncRNAs have been demonstrated to regulate gene expression at almost every stage through epigenetic, transcriptional, and posttranscriptional regulation ${ }^{(24)}$ through a variety of mechanisms of which lncRNAs can base pair with other RNA molecules such as mRNAs or it can be assumed that it works as an endogenous competing RNA, in 
other words may act as endogenous sponges for miRNAs ${ }^{(25)}$.

So, it is recommended to do further studies on the associated genes to the lncRNA.

\section{CONCLUSION}

Serum exosomal LncRNA RP11-510M2.10 increased among control group than among malignant group. LncRNA RP11-510M2.10 expression levels in serum sample could serve as potentially useful noninvasive biomarkers for early diagnosis and prediction of progression of lung cancer.

\section{REFERENCES}

1. Herbst RS, Morgensztern D, Boshoff C (2018): The biology and management of non-small cell lung cancer, 553(7689):446-454.

2. Latimer KM, Mott TF (2015): Lung Cancer: Diagnosis, Treatment Principles, and Screening. Am Fam Physician, 91(4):250-256.

3. Decramer M, Rennard S, Troosters T, Mapel DW, Giardino N, Mannino D,Wouters E, Sethi S, Cooper CB (2008): COPD as a lung disease with systemic consequences-clinical impact, mechanisms, and potential for early intervention. COPD.,5(4):235-56.

4. Boffetta P (2006): Human cancer from environmental pollutants: the epidemiological evidence. Mutat Res., 608(2):157-62.

5. Vineis P, Airoldi L, Veglia F, Olgiati L, Pastorelli R, Autrup H, Dunning A, Garte S, Gormally E, Hainaut P, Malaveille C, Matullo G, Peluso M, Overvad K, Tjonneland A, Clavel-Chapelon F, Boeing H, Krogh V, Palli D, Panico S, Tumino R, Bueno-De-Mesquita B, Peeters $P$, Berglund G, Hallmans G, Saracci R, Riboli E (2005): Environmental tobacco smoke and risk of respiratory cancer and chronic obstructive pulmonary disease in former smokers and never smokers in the EPIC prospective study. BMJ., 330(7486):277.

6. Ruano-Ravina A, Figueiras A, Freire-Garabal M, Barros-Dios JM (2006): Antioxidant vitamins and risk of lung cancer. Curr Pharm Des.,12(5):599-613.

7. Freudenheim JL, Ritz J, Smith-Warner SA, Albanes D, Bandera EV, van den Brandt PA, Colditz G, Feskanich D, Goldbohm RA, Harnack L, Miller AB, Rimm E, Rohan TE, Sellers TA, Virtamo J, Willett WC, Hunter DJ (2005): Alcohol consumption and risk of lung cancer: a pooled analysis of cohort studies. Am J Clin Nutr.,82(3):657-67.

8. Tardon A, Lee WJ, Delgado-Rodriguez $M$, Dosemeci M, Albanes D, Hoover R, Blair A (2005): Leisure-time physical activity and lung cancer: a metaanalysis. Cancer Causes Control,16(4):389-397.

9. Vineis $P$, Husgafvel-Pursiainen $K$ (2005): Air pollution and cancer: biomarker studies in human populations. Carcinogenesis,26(11):1846-1855.
10. Boffetta $P$ (2006): Human cancer from environmental pollutants: the epidemiological evidence. Mutat Res.,608(2):157-162.

11. Boffetta P (2004): Epidemiology of environmental and occupational cancer. Oncogene,23(38):6392-6403.

12.Latimer KM, Mott TF (2015): Lung Cancer: Diagnosis, Treatment Principles, and Screening Am Fam Physician,91(4):250-256.

13. Beckles MA, Spiro SG, Colice GL, Rudd RM (2003): Initial evaluation of the patient with lung cancer: symptoms, signs, laboratory tests, and paraneoplastic syndromes. Chest,123(1):97S-104S.

14. Latimer KM, Mott TF (2015): Lung Cancer: Diagnosis, Treatment Principles, and Screening Am Fam Physician, 91(4):250-256.

15. Raposo G, Stoorvogel W (2013): Extracellular vesicles: Exosomes, microvesicles and friends. J Cell Biol., 200(4):373-83.

16. Nolte-'t Hoen EN, Buermans HP, Waasdorp M, Stoorvogel W, Wauben MH, 't Hoen PA (2012): Deep sequencing of RNA from immune cell-derived vesicles uncovers the selective incorporation of small non-coding RNA biotypes with potential regulatory functions. Nucleic Acids Res.,40(18):9272-85.

17. Tickner JA, Urquhart AJ, Stephenson SA, Richard DJ, O'Byrne KJ (2014): Functions and therapeutic roles of exosomes in cancer.,frontiers in oncology, 4:127.

18. Ricciuti B, Mecca C, Crinò L, Baglivo S, Cenci $M$, Metro G (2014): Non-coding RNAs in lung cancer,. Oncoscience, 15;1(11):674-705.

19.Devaux Y, Zangrando J, Schroen B, Creemers EE, Pedrazzini T, Chang CP, Dorn GW 2nd, Thum T, Heymans S (2015): Cardiolinc network. Long noncoding RNAs in cardiac development and ageing. Nat. Rev. Cardiol., 12: 415-425.

20. Wei MM, Zhou GB (2016): Long Non-coding RNAs and Their Roles in Non-small-cell Lung Cancer. Genomics Proteomics Bioinformatics, 14:280-288.

21. Edge SB, Byrd DR, Compton CC, Fritz AG, Greene FL, Trotti A(2010):AJCC cancer staging manual (7th ed). New York, NY: Springer.

22. Cheng TY,Cramb SM, Baade PD, Youlden DR, Nwogu C, Reid ME (2016): The International Epidemiology of Lung Cancer: Latest Trends, Disparities, and Tumor Characteristics. J Thorac Oncol.,11(10):1653-71.

23. Ohshima K, Inoue K, Fujiwara A, Hatakeyama K, Kanto K, Watanabe Y et al. (2010): Let-7 microRNA family is selectively secreted into the extracellular environment via exosomes in a metastatic gastric cancer cell line. PLoS One, 5: e13247.

24. Morlando M, Ballarino M, Fatica A (2015): Long Non-Coding RNAs: New Players in Hematopoiesis and Leukemia. Front Med.(Lausanne),2:23.

25. Rinn JL, Chang HY (2012): Genome regulation by long noncoding RNAs. Annu Rev Biochem., 81:14566. 